\title{
Embedded Electro-Mechanical Bicycle
}

\author{
Glan Edbarg Mathias ${ }^{1}$, Nelson Fernandes ${ }^{1}$, Supriya ${ }^{1}$, Sachin Prabhu ${ }^{1}$ \\ Department of Electronics \& Communication Engineering, Shri Madhwa Vadiraja Institute of Technology \&
}

Management, Bantakal, India ${ }^{1}$

\begin{abstract}
The project presented here is a user friendly as well as echo friendly vehicle built with Embedded Electro-Mechanical system. Basically bicycle is a two wheeler vehicle which is driven by the muscular power of the rider. The Embedded Electro-Mechanical bicycle is an advance electric power driven, power saving, power generating automatic vehicle. This has got battery back-up system within it. Normally vehicle will not get proper place for parking, it will be outside in hot sunshine even the bicycle are use more during winter and summer season and not during rainy seasons since it as got no top cover. Our system is reliable for these seasons with special care to be taken during rainy seasons while using our Embedded Electro-Mechanical Bicycle. Here two batteries are used one for charging through solar another for discharging for motor. When discharging battery reduces by 2 volt the battery will be automatically switched this is charging battery will start discharging and discharged battery will start charging.
\end{abstract}

Keywords: Gear Box, e-bicycle, Relay module, Arduino.

\section{INTRODUCTION}

Transportation is the means to carry people and goods from one place to another. The bicycle is one which is used by majority of people from age group 4 to 60 plus. It doesn't require any license or insurance as per country law. Bicycle service cost is very low and it doesn't require any external source to ride it.in this modernization no one wants to use their muscular power to ride the bicycle so electric bicycle came into market. But the prize of electric bicycle is too high and it will be difficult for poor and middle class people. The electric bicycle need to be charge for 2 to 3 hours and in case of emergency there will not be power supply to charge in roads. The motor they used is hub or BLDC motors which is costly and battery used by them is lithium ion. The total cost of the product will be nearly equal to that of bike, kinetic, scooty. When the cost is nearly equal then people will not buy electric bicycle instead they go for fuel engine vehicle .The Embedded Electro-Mechanical Bicycle is all about less cost , user friendly and attractive product with only initial cost and it doesn't require power supply to charge it is charged through itself.

\section{LITERATURE REVIEW}

Here in this literature survey, the electric bicycle in market as well as in other journal conference paper where been taken into considered and also the people thoughts and likeness towards the bicycle was analyzed.in market the electric bicycle contains LiPo batteries, hub or BLDC motors and the accelerometer to control the speed .These two battery and hub motors are very costly. The people choose pedal driven bicycle then throttle driven bicycle according to the survey through internet. A visit to "Anthony bicycle works" Udupi was made. The owner of that shop gave information that people won't buy e-bicycle since it as got many limitations and it is difficult to maintain, coming to cost people will go for kinetic or scooty instead of e-bicycle. A visit to nearby school, colleges was done Don Bosco school Shirva, SMVITM Bantakal and we observed children coming to school in school busses and even nearby children coming in auto rickshaws. While talking with children they told if they come with their bicycle they will be tired and can't concentrate in studies during class hour, what about e-bicycle then they was like it is more costly and parents will not offer them e-bicycle. Taking everything into consideration and our knowledge towards electronics and mechanical we came to this product, Embedded Electro-Mechanical Bicycle.

The main aim of this product in less price which is equal to the cost of gear bicycle. LiPo battery is very costly alternate to that we came to know many kinetic batteries will be in scrap because it will loose its main property of initial high discharge .battery will loose this property within 2 years and this battery will not be used in bicycle further. Alternate to hub and BLDC motor which are very costly and got a good torque we are using law torque motors this is radiator motor of air condition in automobiles, these are high speed motors with less torque to increase the torque ,gear box is been introduced 1:7 which will increase the torque. This gear box will be easily available in scrap which is of kinetic. Also came to know from students that they will not have parking facilities and the vehicle will be in hot sunshine outside the compass, taking this into consideration we came up with solar charging system that will charge the battery this became a wonderful advantage of no parking area. 


\section{IJIREEICE \\ International Journal of Innovative Research in Electrical, Electronics, Instrumentation and Control Engineering \\ ISO 3297:2007 Certified \\ Vol. 5, Issue 6, June 2017}

\section{III.METHODOLOGY}

Two batteries have been used these are of $5 \mathrm{AH}, 12 \mathrm{v}$ the motor which is used is radiator motor of air-condition which draws 5amp of current hence one battery will come for one hour. The system as got two modes of operation these are 1) Short distance.

2) Long distance.

In short distance mode one battery will come for 1 hour this is in this mode motor will be ran continues.

In long distance mode inertia energy is used the motor will be turned on for $15 \mathrm{sec}$ and 30sec motor can't be used and hence inertia energy will ride the bicycle forward.

The embedded system is so designed that it won't allow battery to reduce 2 volt i.e., 10v.if the discharging battery is reduced to $10 \mathrm{v}$ then automatic switching will happen now discharged battery will be in charging mode and charged battery will be in discharging mode. Fig. 1 shows the flowchart of the embedded system and Fig. 2 gives the hardware view of the entire model. In this B1 and B2 are two batteries. SP stands for solar panel.

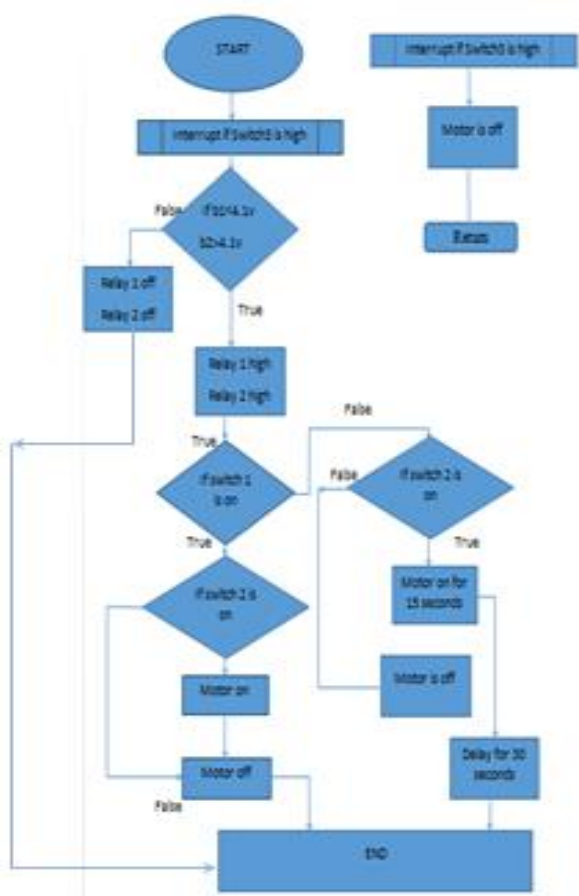

Fig.1 Flowchart of Proposed Method

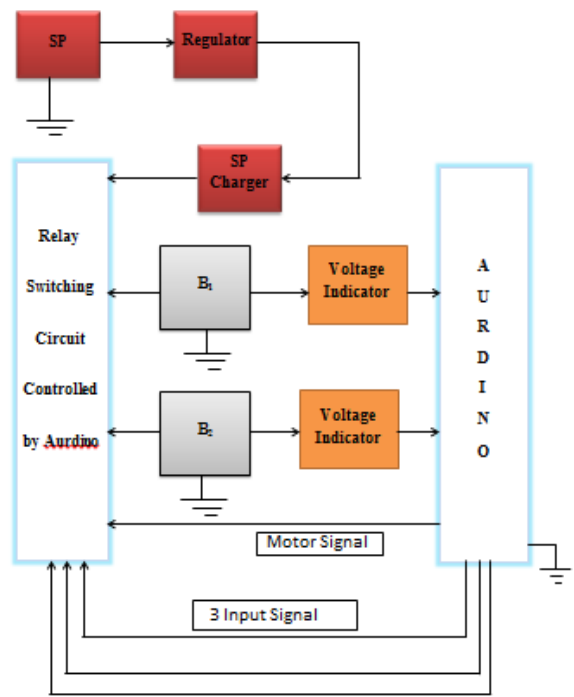

Fig.2 Block Diagram of Proposed Method 


\section{IJIREEICE

\section{VI.HARDWARE IMPLEMENTATION}

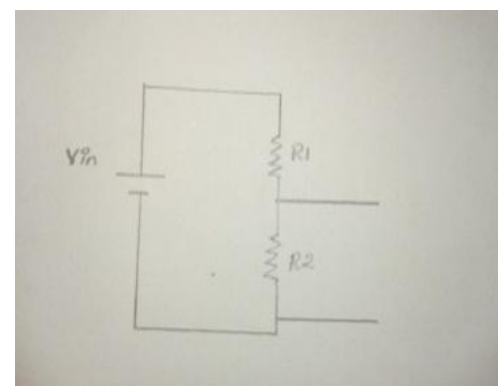

Fig. 3 Voltage Indicator circuit

Voltage indicator circuit: Arduino will not allow more then $5 \mathrm{v}$ as input to indicate the voltage level of $12 \mathrm{v}$ battery below circuit is used i.e., $\mathrm{V}_{\text {out }}=\mathrm{V}_{\text {in }} \mathrm{R} 2 / \mathrm{R} 1+\mathrm{R} 2$ by assuming $\mathrm{R} 2$ as $10 \mathrm{k} \Omega, \mathrm{V}_{\text {out }}=5 \mathrm{v}$ we get $\mathrm{R} 1=15 \mathrm{k} \Omega$, hence $12 \mathrm{v}$ is represented by $5 \mathrm{v}$ if the battery indication goes below 4.1 then the relay will switch such that this battery will go for charging state.

\section{Touch switch circuit}

This is used for breaking system this is when the break is touched the motor will be off; later brake can be pressed for a normal bicycle speed. This circuit will be working in mono-stable state here stable state is low when it is touched high signal will flow which will turn off the motor. A Darlington pair behaves like a single transistor with a high current gain (approximately the product of the gains of the two transistors. In fact, integrated devices have three leads $(\mathrm{B}, \mathrm{C}$, and E), broadly analogous to those of a standard transistor.

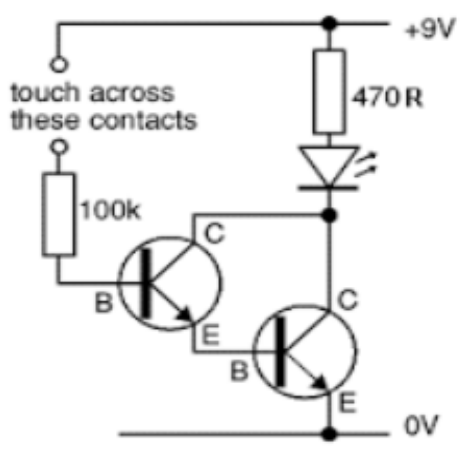

Fig. 4.6 Touch switch circuit

A typical Darlington transistor has a current gain of 1000 or more, so that only a small base current is needed to make the pair switch on. A Darlington pair can be sensitive enough to respond to the current passed by skin contact even at safe voltages. Thus it can form the input stage of a touch-sensitive switch. Darlington transistors can be used in high-current circuits, such as those involving computer controls of motors or relays. The current is amplified from the normal low level of the computer output line to the amount needed by the connected device.

\section{RESULT AND DISCUSSION}

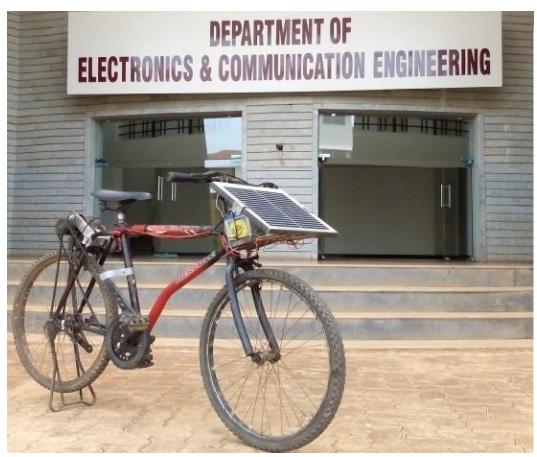




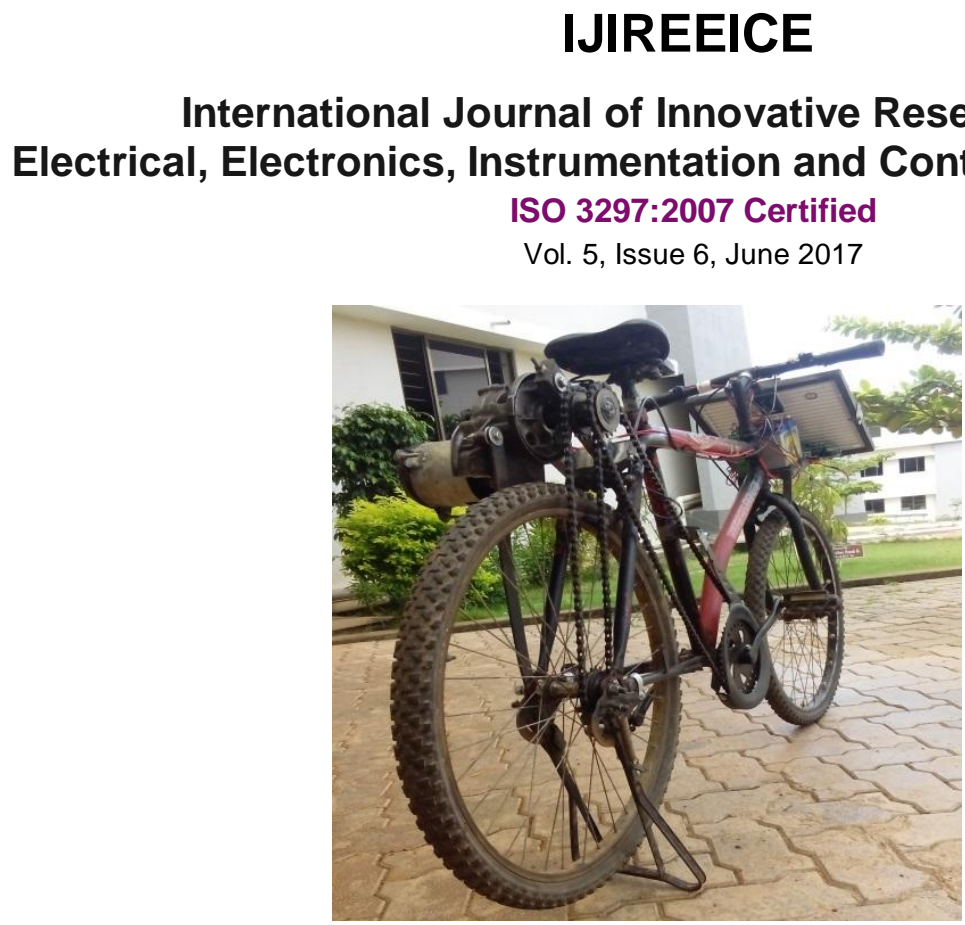

Fig. 5 Overall model

The motor pick up's the speed depending upon the battery used, if the battery is fully charged the motor speed and torque will increase. The rider has to put his muscular energy during initial stage. Later motor will be capable of carrying load of the human.

In the hilly region the pedaling as well as electric motor should be used such that both forces get added and rider can easily climb the hill.

\section{CONCLUSION}

The system is capable to ride with a rider .Comparing to normal bicycle the rider no need of using his muscular power. The charging system is best suited for the bicycle to charge by itself.

\section{REFERENCES}

[1] The Pandit G Patil, Energy Systems Division, Argonne National Laboratory "Advanced Battery Technology for Electric Two-Wheelers"Journal of Energy Systems Division,Argonne National Laborataryjune 2009.

[2] Ahmad A. Pesaran and Tony Markel,Harshad S. Tataria, David Howell "Battery Requirements for Plug-In Hybrid Electric Vehicles Anlysis and Rationale" Conference Paper of National Renewable Energy Laboratory, USA NREL/CP -540-42240 July 2009

[3] Tony Markel, Michael Kuss, and Paul Denholm "Communication and Control of Electric Drive Vehicles Supporting Renewables" Conference Paper of Center for Transportation Technologies and Systems National Renewable Energy Laboratory and System National Renewable Energy Laboratory. NREL/CP-540-46224 August 2009

[4] T. Markel, K. Bennion and W. Kramer ,National Renewable Energy Laboratory and J. Bryan and J. GieddXeel Energy "Field Testing Plug-in Hybrid Electric Vehicles with Charge Report of National Renewable Energy Laboratory, NREL/TP-550-46345, August 2009. 